\title{
An Evaluation of Urban Open Spaces in Larisa, Greece
}

\author{
Charalampos Kyriakidis \\ Ph.D. Candidate, Urban \& Regional Planner, Transportation \\ Engineer, Sustainable Mobility Unit- Department of Geography \& \\ Regional Planning, National Technical University of Athens \\ Efthimios Bakogiannis \\ Transportation Engineer \& Urban Planner, Ph.D., Sustainable \\ Mobility Unit- Department of Geography \& Regional Planning, \\ National Technical University of Athens
}

\section{Abstract}

A great deal of researchers elaborated on the importance of the urban spaces and human life. Urban spaces are necessary types of spaces for a city and they have a timeless value. This research is focused on people's perception about urban spaces in Larisa, Greece, a medium-sized city selected as case study. An electronic questionnaire survey was conducted and conclusions are drawn on how adequate are the urban spaces in Larisa. Moreover, people are asked to propose ideas on how other spaces, function more as urban gaps, can be integrated on the urban grid. In that way, it is easy to study what people believe about the city's life and how the existing urban spaces function. Some conclusions derived from this research can be also useful in succeeding a combined traffic and urban planning in other Greek, in the context of the implementation of a Sustainable Urban Mobility Plan (SUMP).

Keywords: urban spaces, urban gaps, evaluation, questionnaire survey, Larisa.

\section{Introduction}

Urban spaces, from ancient times (Rubenstein, 1992) up to the present day, are a key element of cities. Their role has always been important since it was multidimensional as it served a sequence of functions. These functions, according to some researchers (Stefanou and Stefanou, 1999; Ghel, 2006; Kyriakidis and Siolas, 2014) are the result of the morphology of urban spaces while according to others are the parameters that organize and configure these spaces (Moughtin, 2003; Merleau-Ponty, 1962).

Regardless of the point of view, the study of the function of urban spaces is necessary due to the fact that the public spaces of cities, which are the majority of urban areas, have 
been described as decadent (Loukaitou-Sideris and Banerjee, 1998; Sarigiannis, 1999). The meaning of the function of urban spaces can arise through research at various scales, such as: (a) microscopically: recording static activities that occur in public spaces and recording the number of pedestrians passing through them in order to identify the activities that are being developed in public spaces, recording the frequency of their repetition and investigating the relationship between physical characteristics of the site and the actualization of the respective activities, (b) macroscopically: recording the frequency of use of specific urban areas and identifying the time frame for visiting these sites, studying -at a city level- the satisfaction of residents from urban areas of the city and exploring urban gaps and the desirable way of deploying them, based on citizens' opinion.

The issues that are listed above, make it possible to understand the fact that for a proper study of social life in urban spaces and to comprehend the degree of satisfaction of the public by these spaces and their degree of success, it is necessary to use a series of methodological tools, such as observation and interviews (Lynch, 1960; Whyte , 1980, Mehta, 2009, Kyriakidis, 2016), flaneuring, photography (Kyriakidis, 2016) or short videos (Whyte, 1980) and questionnaire survey.

The combination of the above methods is partly based on the idea of methodological triangulation, which is a practice that is being implemented in the sciences that are related to the study of human behavior (Teddie and Tashakkori, 2011). However, in case of studying the issue that is being described above, due to the range of the subject, the use of various methods approaches to greater degree the view of Yeasmin and Rahman (2012) which defines that it takes place in order to understand the different dimensions of a phenomenon, since the subject of research is interdisciplinary.

Based on the above mentioned, this research paper focuses on recording the degree of satisfaction of residents from the existing urban areas in Larisa, a greek medium-sized city, used as a case study. 


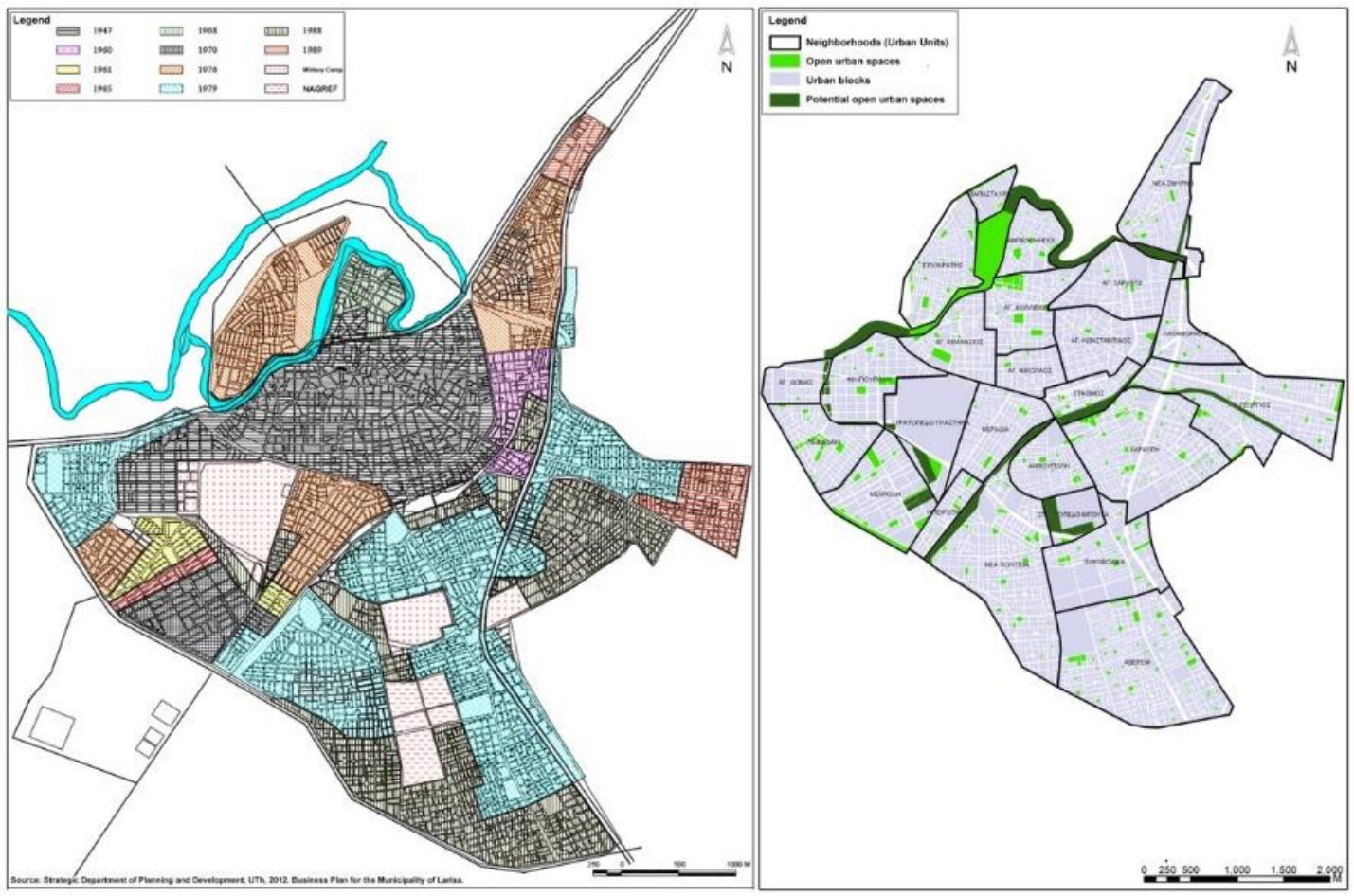

Figure 1. a. Larisa expansion over the years. B. Existing and potential urban open spaces in Larisa. Source: a. Strategic Business Plan for the Municipality of Larisa. (2012). b. Barberis, A. (2007).

\section{Methodology}

This research paper is related to Larisa, a medium-sized Greek city $(143,848$ residents / 2011), which is a typical example of a city with intense urban life, for most of the 24 hours a day (Kyriakides, 2016). The survey was based on a questionnaire survey, conducted electronically from May 2018 to June 2018. The questionnaire contained 15 closed-ended questions or rating scale quetions. Social media have been also used in order to inform the public. Overall, 83 residents of Larisa participated in the survey, men $(54.2 \%)$ and women, 26 to 35 years of age in the majority (50.6\%). Most of them are graduates either from Technological Educational Institutes or from Higher Education Institutions with an area of study in engineering (25.6\%) and human sciences (23.2\%).

It is worth mentioning that the questionnaire design was based on the results from recording of urban areas of the city and their quality, through a field research that was preceded. In addition, data that generated by press clipping concerning the problems of different urban areas and the intentions of local authorities relating to them have also been used. 
The findings of the survey about the degree of satisfaction that urban areas offer are specifically related to Larisa and cannot be generalized in other cities. However, through the survey, suggestions are made for the use of potential urban areas, a fact that can be generalized in similar cases, as with this way it: (a) identifies the reasons that make some areas potentially urban, (b) formulates ideas for the uses that these areas could have and (c) expresses the importance of space management and by whom. These issues are important and relevant to the planning that is being implemented in all Greek cities.
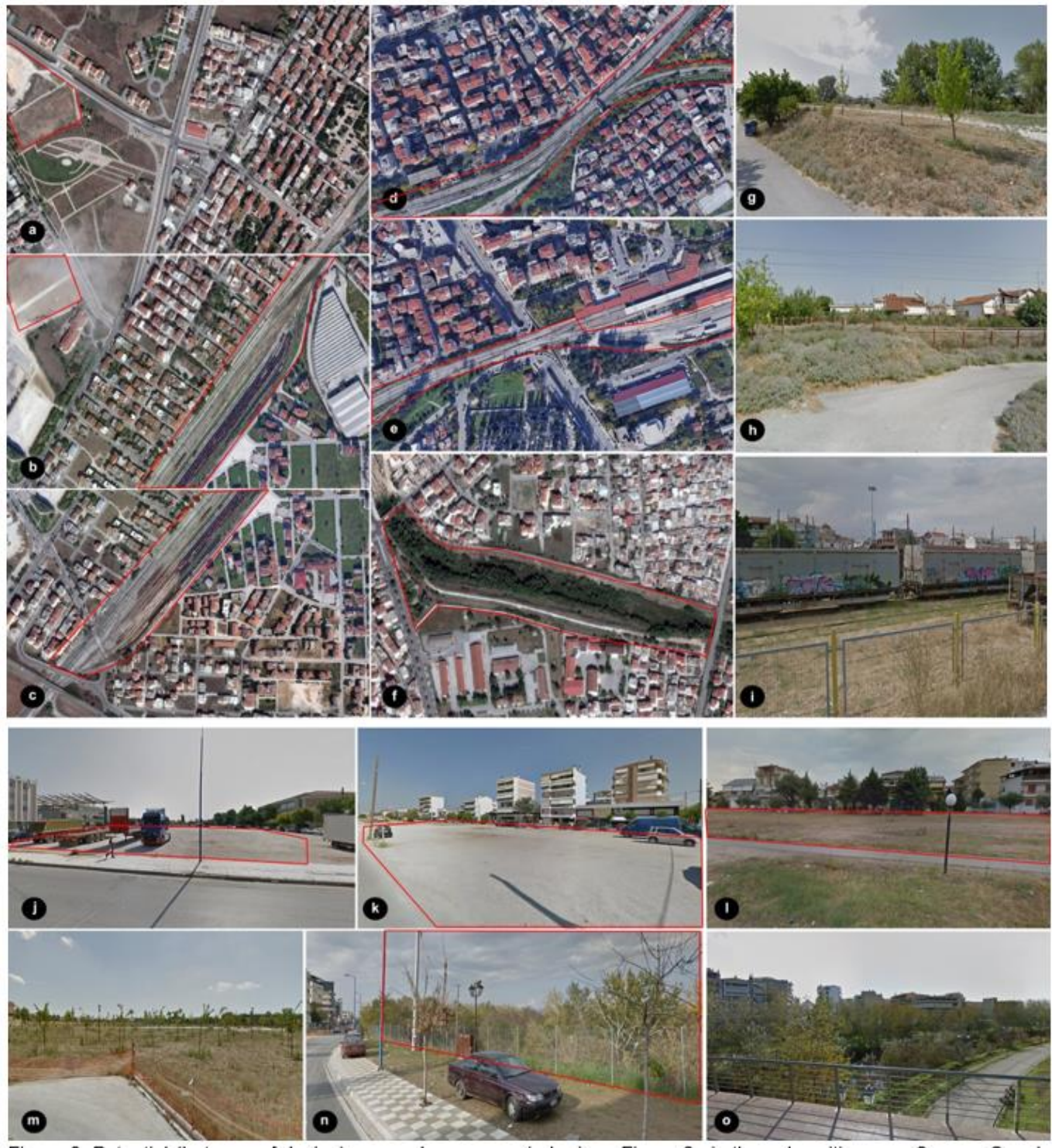

Figure 2. Potential (In terms of design) open urban spaces in Larisa. Figure 20 is the only exiting one. Source: Google Street View. 


\section{Discussion with citizens}

Larisa is a medium-sized town located approximately in the geographical center of Greece. Since prehistoric times, its center is the Fortress Hill, and a large part of the central area consists of urban spaces. There is also a large number of urban spaces in the other central areas and neighborhoods of the city, since Larisa had been expanded considerably in the twentieth century (Figure 1a). Squares, green spaces, parks and roads, large or small in width, are among the urban areas of the city.

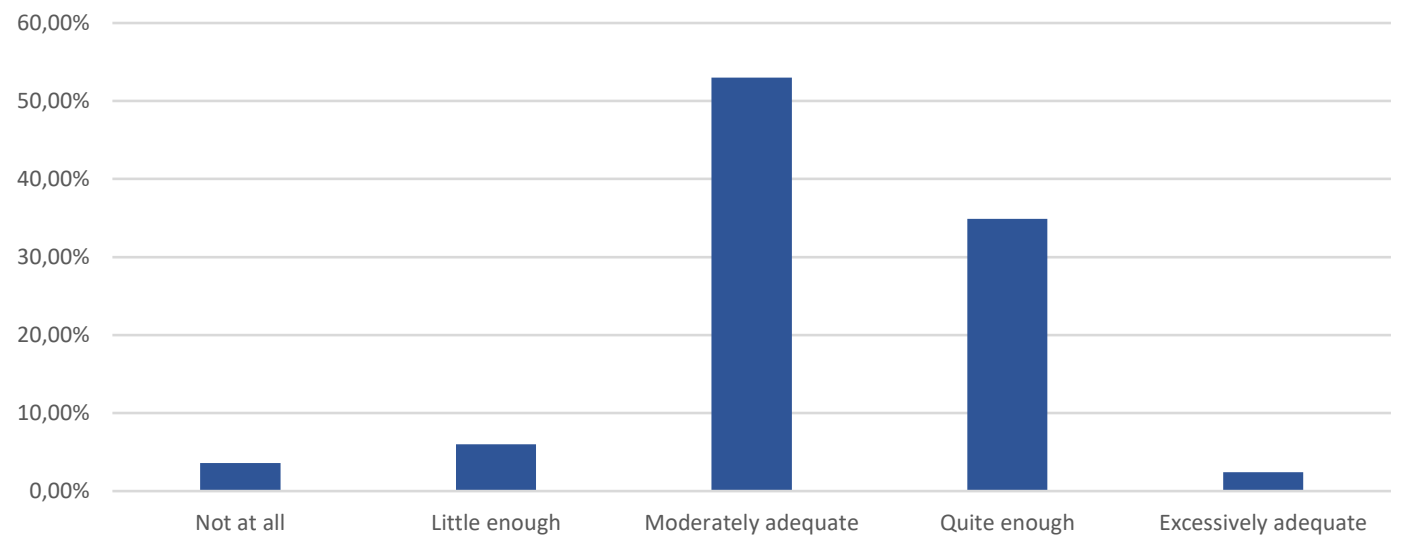

Figure 1b illustrates the urban open spaces and green spaces in Larisa, which are emphasized in the context of this survey. Emphasis is also placed on some other areas that have been criticized as dysfunctional or urban gaps (Figure 1b). As can be clearly seen from Figure 1b, urban areas of Larisa are almost evenly distributed in the city, with most of the urban open spaces being situated in the northern and western parts of it. This means that the residents of Larisa are expected to be satisfied due to the adequacy of the existing urban areas of the city. However, in the questionnaire survey, 53\% of respondents hold a neutral stance, with only $37.3 \%$ of the respondents considering the existing sites as satisfactory in terms of their configuration and adequate in number (Diagram 1). Although in Larissa, there are four large green areas (riparian area in the city center, Alcázar Park, Hatzi-chalaar Park and the Aesthetic Park); however, the majority of respondents believe that green is the missing element of urban areas of the city (72.1\%). Actually, the absence of green, may be a cause that $36.1 \%$ does not use as much as they would like the urban areas of the city (Diagram 2). This interpretation may also be related to the fact that most of the residents choose the urban areas of the city center $(60.2 \%)$ and not the ones of neighborhoods (39.8\%), although the neighborhood squares are the main public spaces of neighborhoods. 


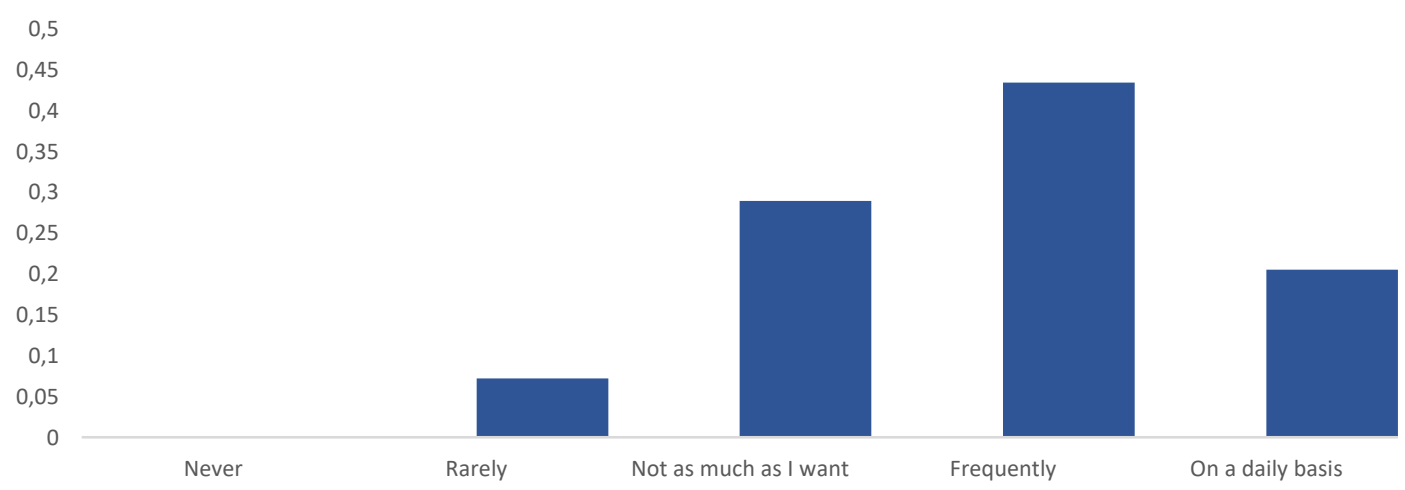

Diagram 1. How adequate are the urban spaces in Larisa? 53\% of respondents hold a neutral stance, with only $37.3 \%$ of the respondents considering the existing sites as satisfactory in terms of their configuration and adequate in number. Source: Own elaboration.

Diagram 1. People in Larisa prefer to visit open spaces, quite often. However, the absence of green, may be a cause that $36.1 \%$ does not use as much as they would like the urban areas of the city. Source: Own elaboration.

In the framework of the same survey, respondents were asked to give their opinion on a number of sites, such as (Figure 2):

- the riparian zone outside the city center, which is not part of the urban fabric. This certain area is unformulated but lies within the urban area, in the northern and eastern parts of the city and today it acts as a boundary between two districts (Agioi Saranda and Nea Smyrni). It is worth mentioning that the General Development Plan for the Municipality of Larissa (2009) predicts the configuration of this area as green spaces and sports facilities.

- the railway line in the south-eastern part of the city, according to Kevin Lynch's (1960) theoretical approach, acts as a functional boundary between the northern and southern parts of the city, as well as the western and the central with the eastern. Actually, the area that covers in the southern part of the city is important, given the presence of a depot and several rail lines. Along the urban section of the railway lines many fatal incidents have occurred. A typical case was the incident with victim a child 10 years old in November 2017 that triggered social reactions (Iefimerida, 2017), and was the reason for discussions in the Hellenic Parliament about the undergrounding of the railway line (Mavroyiannis, 2017) a suggestion that had been proposed by Larisa Strategic Business Plan (2012). 
- the military camps, which have occasionally been attempted by the municipality of Larissa for the concession of army land for the purpose of creating urban spaces and the construction of public land. In this context, spaces of the 1st Army were granted for the opening of a road and the construction of a primary school. In September 2017, there was also the question of granting important land within the city for exploitation by the municipality (Kakaras, 2017). Like the issue of underground railway lines, the removal of the camps was also proposed by Larisa Strategic Business Plan (2012). According to the General Development Plan for the Municipality of Larissa (2009), planning for the relocation of a camp from the area within the project is required to meet the green needs.

- the Hatzi-chalaar Moat -located close to the Bazaar area that is used only a few days within the year-, for which integration into the city was declared an architectural competition in 2008. Although a part of the planned regeneration was implemented resulting in the construction of a park, a large part of the area was left untapped and today it is a vacant area most of the time, is an informal parking area.

Are there any open spaces that should be integrated in the urban grid?

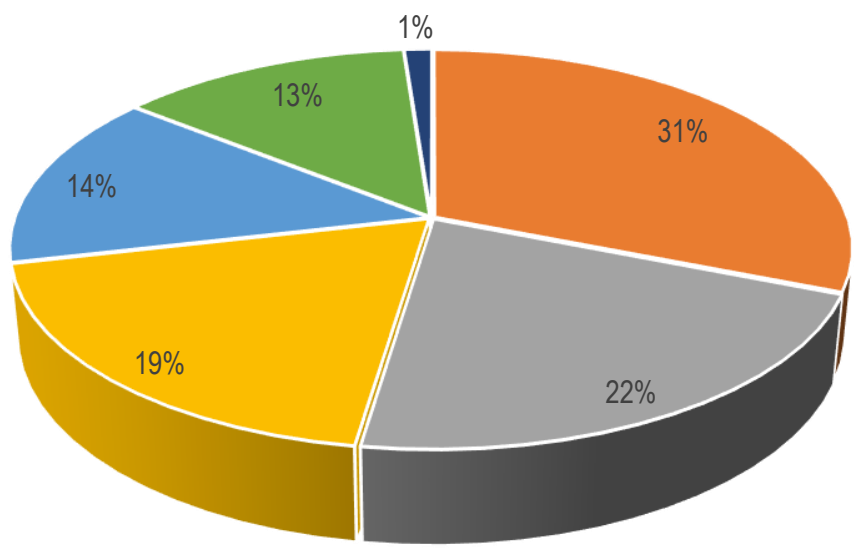

- Riparian zone outside the city center

- Military Camps

- Railway lines

- Hatzi-chalar Moat

- Bazaar area

- Riparian zone inside the city center

Diagram 3. The most important open space that should be integrated in the urban grid is the riparian zone, outside the city center. Source: Own elaboration.

Of the above sites, the riparian zone outside the center was assessed as the most important untapped area (31\%) (Diagram 3), because they consider it to be an area of natural beauty, but due to the fact that it has not been shaped (41\%), it also cannot be exploited. However, there were many respondents who evaluated as significant the use of some military areas $(21.4 \%)$ and the surface of the railways in the city (19\%) (Diagram 3). The above answers were motivated by the fact that the aforementioned 
sites create problems in the neighborhood communication (25.3\%). In order to make better use of the above areas, in the majority of cases (50\%), respondents asked for green spaces to be created. The paradox is that although the number of cafes in Larisa is big (1,674 cafes, 2014) (Iefimerida, 2014), 19\% of respondents suggested the development of new recreation areas (Diagram 4). The proposal for the creation of urban vegetable gardens was proposed by only $8.3 \%$ of respondents, obviously, for the integration of the undeveloped riparian zone (Diagram 4).

What do you think better in order for the open space to be integrated in the urban grid?

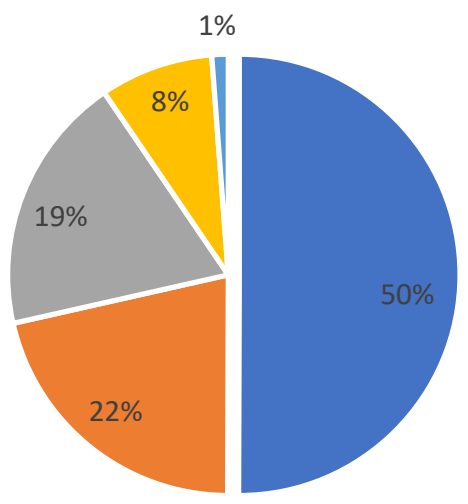

- Development of green spaces (park or
urban square)
- Redesigning the space and retaining its
existing use
- Development of shopping areas or cafés
and restaurant cluster
- Development of a communal/urban
(vegetable) garden
- It Is not possible for the space to be
integrated

Diagram 3. The most important open space that should be integrated in the urban grid is the riparian zone, outside the city center. Source: Own elaboration.

$80.9 \%$ of respondents believe that the development of a new urban park would greatly encourage the use of the aforementioned sites, with a primary positive impact on citizens being the improvement of the quality of life (63.4\%). $24.4 \%$ of respondents believe that through such an intervention, the urban landscape of the city will improve, which will help to attract investment, a fact that is theoretically supported (Gospodini, 2002; Gospodini, 2006; Kyriakidis and Siolas, 2013; Athanasopoulou and Giannakopoulos, 2018).

Finally, it was considered appropriate to identify the attitude of the inhabitants to the management of a new urban park. This issue has been studied in the international bibliography (Martin, 2013; Kyriakidis and Siolas, 2014; Han, Hawken and Williams, 2015; Khairi, et.al., 2017) and has become relevant in the context of an effort to upgrade such several sites, such as Pedion Areos and Tritsi Park in Athens. The questionnaire survey revealed that $63.1 \%$ of respondents are positive in setting up a management body to ensure the high quality maintenance of the site. In fact, $54.5 \%$ of them agree with the management of the space by a private individual, although the sites in question are expected to be common. In this way, it is noted that the public character of the urban 
space does not need to be based on property or management issues, but it should be more closely related to how it operates and the people who can use it.

Summarizing the above, we can conclude that although the existing urban areas in Larisa partially satisfy their inhabitants, there is room for further exploitation of areas where urban green can play a dominant role. The general change in the lifestyle of the past few years, to outdoor recreation and sports, degrading entertainment in cafes and restaurants, is also obvious in the case of Larisa, as shown by this questionnaire survey. In this context, the development of open public urban spaces tends to be one-way street for the best satisfaction of the modern needs of its inhabitants.

\section{Conclusions}

Although the use of open public urban spaces has been the focus of criticism for several times, since these spaces have been considered as decadent, for different reasons in different areas, their role is nevertheless considered to be indisputable, especially in European cities, which have been historically developed around such areas and until nowadays are their hearts. In this context, this paper explores the extent to which the residents of Larisa are satisfied with the existing urban spaces. As it emerged, although the existing urban areas in Larisa partly satisfy its inhabitants, there is room for: (a) aesthetic improvement of existing sites; and (b) creation of new urban spaces. The implementation of the Sustainable Urban Mobility Plan (SUMP) of Larisa as well as the urban regeneration projects funded by the NSRF in the framework of the Integrated Spatial Investment of ISI-SUD, at this time, is expected to contribute significantly to the improvement of the image of urban areas and mostly of the existing urban areas. However, these circumstances can be used to extend the city's recreation networks, while creating green paths.

In this sense, the above questionnaire survey revealed that in Larissa, nowadays, there are spaces that by being unformulated or by restricting the access of the public to them, they act as limits for the communication between neighborhoods of Larisa and prevent their further exploitation and viewing of the city. Such linear spaces are the riparian zone outside the city center, which can act as a backbone for the development of green path networks. The combination of a corresponding green route along the railway lines can achieve the development of a green ring around the center, thus giving all residents equal access to high-quality green areas for mild recreation and sports. Such interventions can be examples of planning in other Greek cities as well. Actually, the integration of such interventions in the context of the SUMP projects implemented in Greek cities can contribute to the achievement of unified planning in the context of policies for a solid and sustainable city.

\section{References}

[1] Athanasopoulou, E. and Giannakopoulos, N. (2018). Kalamata Dance Hall: A new landmark in the city. Chorografies, 5(1), pp. 1-9. 
[2] Barberis, A., 2007. Analysis and evaluation of the assurance of urban open spaces using heterogeneous primary data: Comparative approach to Volos and Larisa. Analysis and Evaluation of the Assurance of Urban Spaces using heterogeneous primary data. Comparative Approach to Volos and Larissa - M.Sc. Thesis, Department of Planning and Regional Development, University of Thessaly.

[3] General Development Plan for the Municipality of Larisa, B2 Phase. (2009).

[4] Gehl, J. (2006). Life between buildings: using public space. Translated from Danish by J. Koch. Washington, DC; London: Island Press.

[5] Gospodini, A. (2002). European Cities in Competition and the New "Uses" of Urban Design. Journal of Urban Design, 7(1), pp. 59-73.

[6] Gospodini, A. (2006). Sketching, interpreting and collating the new landscapes of postmodern city. In Gospodini, A. and Beriatos, E. (Eds.) The new urban landscapes and the Greek city. Athens: Kritiki Publications, pp. 27-50.

[7] Han, J.H., Hawken, S. And Williams, A. (2015). Smart CCTV and the management of urban space. In: Harrison, D. (Ed) Handbook of Resarch on Deigital Media and Creative Technologies, Hershey, PA: IGI Global, pp. 430-447.

[8] Iefimerida. (2014). Unbelievable: Larisa is emerging in... a city of coffee with 1.674

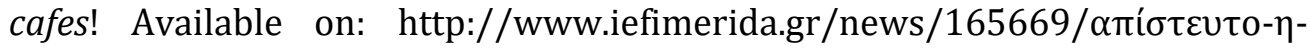

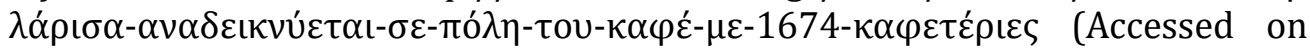
$20^{\text {th }}$ June 2017).

[9] Iefimerida. (2017). Larisa: Roma are blocking the rail lines on Sunday. Available on: $\quad$ http://www.iefimerida.gr/news/375154/larisa-se-apokleismo-tongrammon-toy-ose-prohoroyn-oi-roma-tin-kyriaki (Accessed on $20^{\text {th }}$ June 2017).

[10] Kakaras, V. (2017). Signatures are signed for the camps. Available on:

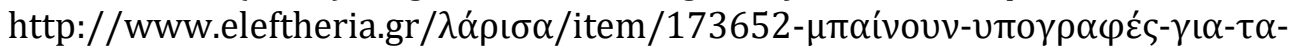
$\sigma \tau \rho \alpha \tau o ́ \pi \varepsilon \delta \alpha . h t m l ~\left(A c c e s s e d ~ o n ~ 20^{\text {th }}\right.$ June 2017).

[11] Khairi, M.A., Abdulla, M.G.A. and Gehna, S. (2017). Walkability in historic urban spaces: Testing the safety and security in Martyr's Square in Tripoli. ArchiNetInternational Journal of Architectural Research (IJAR), 11(3), pp. 163-177.

[12] Kyriakidis, C. (2016). The function of urban public square in relation to local parameters: Comparative study between Larisa and Nottingham. Aeichoros, 24, pp.67-85.

[13] Kyriakidis, C. and Siolas, A. (2014). The sense of safety as an urban 38evelopment parameter: The case study of the center of Athens. 12th Regular Scientific Conference of the Greek Deparment of the European Society of Regional Science (ERSA-GR): Urban and regional development, Modern Challenges, Athens, Greece, 27-28 June 2014. 
[14] Loukaitou-Sideris, A. and Banerjee, T. (1998). Urban Design Downtown. Poetics and Politics of Form, Berkley; Los Angeles, Calif.; London, UK: University of California Press.

[15] Lynch, K. (1960). The image of the city. Cambridge, MA and London: The MIT Press.

[16] Martin, D. (2013). Police, urban space, politcs and reasonability. Urban Geography, 33(7), pp. 936-939.

[17] Maurogianni, M. (2017). Making underground the railway lines or making them to bypass the city. Available on: http://www.ert.gr/perifereiakoistathmoi/larisa/ypogiopiisi-parakampsi-ton-sididromikon-grammon/ (Accessed on 20th June 2017).

[18] Mehta, V. (2009). Look closely and you will see, listen carefully and you will hear: Urban deisgn and social interaction on streets. Journal of Urban Design, 14(1), pp. 29-64.

[19] Merleau-Ponty, M. (1962). Phenomenology of Pereption, London; New York: Routledge.

[20] Moughtin, C. (2003). Urban design: street and square. $3^{\text {rd }}$ ed. Oxford: Architectural Press.

[21] Rubenstein, H. (1992). Pedestrian malls, streetscapes, and urban spaces. New York,Chichester, Brisbane, Toronto and Singapore: John Wiley and Sons, Inc.

[22] Sarigiannis, J. (1999). Public Squares: Urban space in an era of decline. Architects, 13B, pp. 25-26.

[23] Stefanou, I. and Stefanou, J. (1999). A description of the image of the city. Athens: NTUA Publications.

[24] Strategic Business Plan for the Municipality of Larisa. (2012).

[25] Teddie, C. and Tashakkori, A. (2011). Contemporary issues in an emerging field. In: Denzin, N. and Lincoln, Y. (eds). The SAGE Handbook of qualitative research 4. Los Angeles (CA), London (UK), New Delhi, Singapore, Washington DC: SAGE Publications Inc. pp. 285-300.

[26] Whyte, W. (1980). The social life of small urban spaces. Washington, D.C.: Conservation Foundation.

[27] Yeasmin, S. and Rahman, F. (2012). Triangulation' Research Method as the Tool of Social Science. BUP Journal, 1(1). Pp. 154-163. 